\title{
Meghan Craven and Graeme R. Frank* \\ Does initial dosing of levothyroxine in infants with congenital hypothyroidism lead to frequent dose adjustments secondary to iatrogenic hyperthyroidism on follow-up?
}

https://doi.org/10.1515/jpem-2017-0513

Received December 7, 2017; accepted April 3, 2018; previously published online May 1, 2018

\section{Abstract}

Background: Congenital hypothyroidism $(\mathrm{CH})$ is the most common preventable cause of intellectual disability. The recommended starting dose of levothyroxine (LT4) is between 10 and $15 \mu \mathrm{g} / \mathrm{kg}$, an extremely wide range. We hypothesized that a sizable proportion of newborns treated for $\mathrm{CH}$ at the higher end of the dosage range become biochemically hyperthyroid at a follow-up visit.

Methods: This study is a retrospective chart review of infants with CH between 2002 and 2012.

Results: Of the 104 patients included in this analysis, the average age at diagnosis was 11 days and the average starting dose of LT4 was $12 \pm 2.5 \mu \mathrm{g} / \mathrm{kg}$. At follow-up, 36.5\% required a dose reduction because of iatrogenic hyperthyroxinemia, 51\% required no dose adjustment and 12.5\% required a dose increase due to an elevated thyroid stimulating hormone (TSH). The starting doses of LT4 for those requiring a dose reduction, those not requiring an adjustment and those requiring an increase in the dose were $13.2 \pm 2.4,11.5 \pm 2.1$ and $10.3 \pm 2.6 \mu \mathrm{g} / \mathrm{kg} /$ day, respectively ( $\mathrm{p} \leq 0.0001)$. Of the $34 \%$ of infants treated with an initial dose of $>12.5 \mu \mathrm{g} /$ day, $57.1 \%$ required a dose reduction at follow-up, compared to $26.1 \%$ of those whose initial starting dose was $\leq 12.5 \mu \mathrm{g} / \mathrm{kg} /$ day $(\mathrm{p}=0.007)$.

Conclusions: Following the guidelines for initiating therapy for $\mathrm{CH}, 36.5 \%$ of the infants required a dose reduction for iatrogenic hyperthyroxinemia. These infants received a higher dose of LT4 than the infants who either required no adjustment or required an increase in the dose. A narrower range for initial dosing in $\mathrm{CH}$ may be appropriate.

\footnotetext{
*Corresponding author: Graeme R. Frank, MD, Division of Pediatric Endocrinology, Cohen Children's Medical Center, Hofstra Northwell School of Medicine, 1991 Marcus Avenue, Suite M100 Lake Success, New Hyde Park, NY 11042, USA, Phone: +(516) 472-3750, Fax: +(516) 328-1702, E-mail: gfrank@northwell.edu Meghan Craven: Division of Pediatric Endocrinology, Cohen Children's Medical Center, Hofstra Northwell School of Medicine, New Hyde Park, NY, USA
}

Keywords: congenital; dose; hypothyroidism; levothyroxine.

\section{Introduction}

Congenital hypothyroidism $(\mathrm{CH})$ is the most common preventable cause of intellectual disability with an incidence estimated to be 1:2000-1:3000 in countries with neonatal screening programs $[1,2]$. In order to achieve the best outcome, both adequacy and timing of replacement therapy are critical, especially in severe cases. The goal of therapy is to normalize the thyroxine (T4) within 2 weeks and thyroid stimulating hormone (TSH) within 1 month, in order to reduce the exposure of the infant's central nervous system to hypothyroidism and ensure that the infant's growth and development reach their genetic potential [3, 4]. However, what constitutes optimal therapy has not yet been fully determined.

The current guidelines recommend starting levothyroxine (LT4) at an initial dose between 10 and $15 \mu \mathrm{g} / \mathrm{kg}$ [5]. This is a large dosing range and the dosage used is frequently influenced by the available tablet strengths which are the following in the US: $25 \mu \mathrm{g}, 37.5 \mu \mathrm{g}(1 / 275 \mu \mathrm{g}$ tablet), $44 \mu \mathrm{g}(1 / 288 \mu \mathrm{g}$ tablet) and $50 \mu \mathrm{g}$. Adhering to the $10-15 \mu \mathrm{g} / \mathrm{kg} /$ day dosage, a $2.4-\mathrm{kg}$ infant will generally be started on $25 \mu$ g daily $(10.4 \mu \mathrm{g} / \mathrm{kg}$ daily), while a $2.6-\mathrm{kg}$ infant will receive $37.5 \mu \mathrm{g}$ daily $(14.4 \mu \mathrm{g} / \mathrm{kg}$ daily), a dose that is $42 \%$ larger than the $2.4-\mathrm{kg}$ newborn's dose.

The aim of this study was to focus on the incidence of overtreatment given this extremely wide dosing range. We hypothesized that a sizable proportion of newborns with $\mathrm{CH}$ treated at the higher end of the dosage range become biochemically hyperthyroid at follow-up visit, requiring a reduction of the dose.

\section{Materials and methods}

This study is a single-center, retrospective chart review at Cohen Children's Medical Center between January 1, 2002 and December 31, 2012 focusing on patients with $\mathrm{CH}$ treated by physicians working at the practice during this time period. The study was approved by the Institutional Review Board of our health system. Inclusion criteria 
were newly diagnosed patients with $\mathrm{CH}$ identified by the New York State newborn screening program, presenting within the first month of life and in whom elevated TSH of greater than or equal to $20 \mathrm{mIU} / \mathrm{L}$ was confirmed on repeat laboratory testing. Exclusion criteria included (a) patients with Down syndrome, (b) patients with transient hypothyroidism, defined as patients able to be weaned off LT4 replacement therapy by 3 years of age, (c) patients lost to follow-up due to switching practices and (d) patients with documented poor compliance. Data collected included the following: age at diagnosis (days), gender, weight at first visit (kg), confirmatory TSH at diagnosis $(\mathrm{mIU} / \mathrm{L})$, starting LT4 dose $(\mu \mathrm{g} / \mathrm{kg} /$ day), age at follow-up (days), length of treatment at follow-up (days), TSH at follow-up (mIU/L) and dose adjustment performed by the physician. In addition, charts were reviewed to determine the reason for dose adjustment and trends in practices. The normal range for TSH at follow-up was defined as $0.9-8.0 \mu \mathrm{IU} / \mathrm{mL}$, a low TSH as $0.1-0.89 \mu \mathrm{IU} / \mathrm{mL}$ and a suppressed TSH as $<0.1 \mu \mathrm{IU} / \mathrm{mL}$.

The primary outcome of the study was the percent of patients requiring a dose reduction at follow-up. Differences between the groups were analyzed using analysis of variance (ANOVA). A further analysis was done looking at the percentage of patients requiring a dose change after dividing the patients into those whose initial dose of LT4 was less than or equal to $12.5 \mu \mathrm{g} / \mathrm{kg} /$ day and those whose initial dose was greater than $12.5 \mu \mathrm{g} / \mathrm{kg} /$ day. Groups were compared using the chi-square test to determine statistical significance.

\section{Results}

A total of 141 patients were identified, of which 37 were excluded based on the above-mentioned exclusion criteria. Of the 104 patients included in this analysis, the average age at diagnosis was 11 days ( $\mathrm{SD} \pm 6$ days) and the average starting dose of LT4 was $12 \pm 2.5 \mu \mathrm{g} / \mathrm{kg}$.

At follow-up, 36.5\% required a dose reduction, 51\% required no dose adjustment and $12.5 \%$ required an increase in the dose (Figure 1). Focusing on the 36\% (38 of the 104) assessed to be biochemically hyperthyroid and requiring a dose decrease, 29 had a low/suppressed TSH and nine had an elevated T4 with a normal TSH as the basis for the dose adjustment (Figure 2, light gray bar). Fifty-three of the 104 patients were assessed to be euthyroid requiring no medication change. Of these, 18 of the 53 patients had a low/suppressed TSH but were kept on the same dose with the idea that the patients would grow into their dose and practitioners allowed for permissive hyperthyroidism (Figure 2, intermediate gray bar). Thirteen of the 104 patients were assessed clinically to be hypothyroid requiring a dose increase after 20-40 days of treatment. Of these, 12 were for an elevated TSH ranging from 8.59 to $82.65 \mu \mathrm{IU} / \mathrm{mL}$ (Figure 2), and one was for a low T4 with a normal TSH of $4.7 \mu \mathrm{IU} / \mathrm{mL}$ (Figure 2, dark gray bar). Only five patients had a TSH of $>15 \mu \mathrm{IU} / \mathrm{L}$ at followup and four of these five patients were treated with an initial dose of less than $11.4 \mu \mathrm{g} / \mathrm{kg} /$ day.

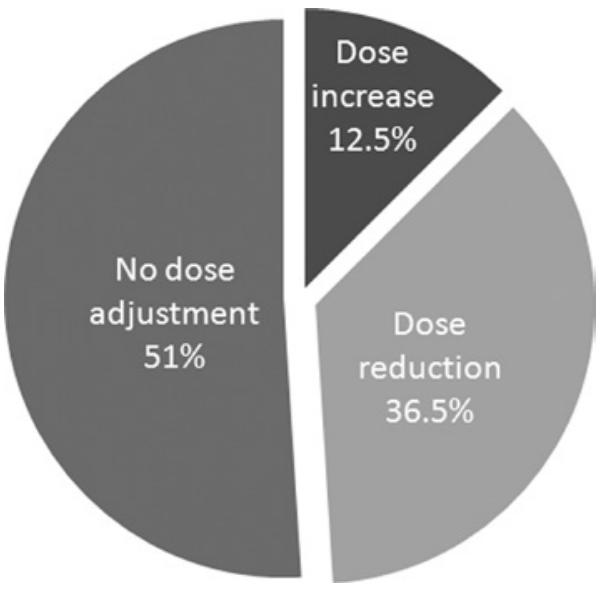

Figure 1: Follow-up dose adjustment based on practitioner's assessment.

Dark gray = subjects requiring a dose increase, light gray= subjects requiring a dose reduction and intermediate gray= subjects not requiring a dose adjustment.

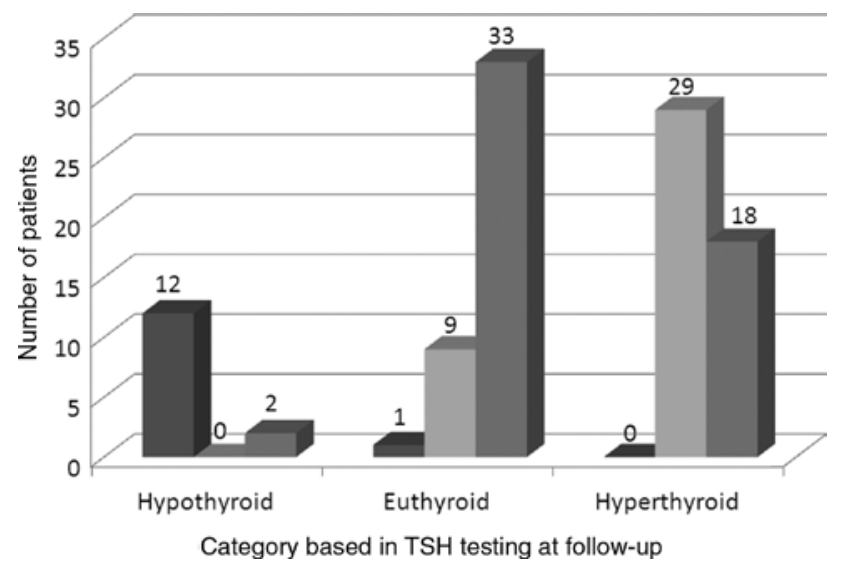

Figure 2: Clinical practice vs. laboratory testing.

The hypothyroid group had elevated TSH, the euthyroid group had normal TSH and the hyperthyroid group had low/suppressed TSH.

Dark gray= subjects whose dose was increased, light gray= subjects whose dose was decreased and intermediate gray= subjects whose dose was not adjusted.

The starting dose of LT4 for those requiring a dose reduction, those not requiring an adjustment and those requiring an increase in the dose was $13.2 \pm 2.4,11.5 \pm 2.1$ and $10.3 \pm 2.6 \mu \mathrm{g} / \mathrm{kg} / \mathrm{day}$, respectively ( $\mathrm{p} \leq 0.0001)$.

When dividing the patients into those treated with an initial dose of LT4 of $>12.5 \mu \mathrm{g} / \mathrm{kg} /$ day and those whose initial starting dose was $\leq 12.5 \mu \mathrm{g} / \mathrm{kg} /$ day, it was noted that $57.1 \%$ of the infants treated with an initial dose of $>12.5 \mu \mathrm{g} /$ day required a dose reduction, compared to $26.1 \%$ of those who were started at a dose of $\leq 12.5 \mu \mathrm{g} / \mathrm{kg} /$ day $(\mathrm{p}=0.006573)$, Table 1 . Similarly, $5.7 \%$ 
Table 1: Differences in higher vs. lower dosage range.

\begin{tabular}{lrr}
\hline & $\begin{array}{r}\text { Started at } \\
\leq 12.5 \mu \mathrm{g} / \mathrm{kg}\end{array}$ & $\begin{array}{r}\text { Started at } \\
>12.5 \mu \mathrm{g} / \mathrm{kg}\end{array}$ \\
\hline \% Requiring dose reduction & $26.1 \%$ & $57.1 \%$ \\
\% Requiring dose increase & $15.9 \%$ & $5.7 \%$ \\
\hline
\end{tabular}

Percent of patients requiring dose adjustments when divided into those with an initial dose of LT4 of $>12.5 \mu \mathrm{g} / \mathrm{kg} /$ day and those whose initial starting dose was $\leq 12.5 \mu \mathrm{g} / \mathrm{kg} /$ day.

of the infants treated with an initial dose of $>12.5 \mu \mathrm{g} /$ day required a dose increase, compared to $15.9 \%$ of those who were started at a dose of $\leq 12.5 \mu \mathrm{g} / \mathrm{kg} /$ day $(\mathrm{p}=0.0238$ [Table 1]).

The mean age at dose adjustment was $49 \pm 23$ days which occurred after $36 \pm 22$ days of treatment with no significant difference in the duration of treatment between patients who were hypothyroid, euthyroid or hyperthyroid on laboratory evaluation (the average duration of treatment at follow-up was 36, 36.6 and 36.3 days for hypothyroid, euthyroid and hyperthyroid, respectively). This means that routine monitoring of thyroid function tests (TFTs) every 2 weeks was not performed due to both compliance and large variability of practice strategies among providers, some of whom relied on TSH to assess the adequacy of the dose of LT4.

\section{Discussion}

Historically in the 1970s and 1980s, children with CH were treated with a LT4 dose of 5-10 $\mu \mathrm{g} / \mathrm{kg} /$ day. In addition, at that time treatment usually was not started within the first 14 days of life. Intellectual outcomes of these children were significantly lower than those of healthy controls which raised concerns regarding the adequacy of the treatment. As a result, higher initial doses of thyroid replacement therapy were recommended as well as earlier initiation of therapy, within the first 14 days [5].

The current guidelines recommend starting LT4 at an initial dose between 10 and $15 \mu \mathrm{g} / \mathrm{kg}$, and then checking TSH and T4 every 2 weeks until TSH normalizes and then every 1-3 months during the first 12 months of life [1]. Some have advocated for an even higher initial dose of $12-17 \mu \mathrm{g} / \mathrm{kg}$, as studies have shown that in this range the serum T4 normalizes in 3 days and the TSH returns to the target range by 2 weeks $[6,7]$. However, the latter dose recommendation has taken an already wide dosing range and made it even wider with mixed data showing no conclusive benefit. Studies such as Selva et al. [8] showed that TSH normalization within 2 weeks resulted in higher cognitive, attention and achievement scores. However, the effects of overtreatment and the resulting transient iatrogenic hyperthyroidism are unknown. Immediate effects are difficult to study given the fact that studies looking at behavior (sleep patterns, agitation, excessive crying, etc.) and growth are difficult to perform due to confounding factors. However, a study by Bongers-Schokking et al. looked at the long-term effects of overtreatment in $\mathrm{CH}$ during the first 2 years of life, defined as free T4 concentrations greater than 2 standard deviations above the mean for age, and showed that overtreatment actually resulted in lowered cognitive outcomes measured by intelligence quotient (IQ) at 11 years of age compared to undertreatment. However, once again fast TSH normalization did lead to above-normal development scores at a young age but did not affect IQ at 11 years of age [9]. Similarly Dimitropoulos et al. followed-up 63 children with $\mathrm{CH}$ who were treated with a starting dose of LT4 of $14.7 \mu \mathrm{g} / \mathrm{kg} /$ day and assessed their IQ at 14 years. Their IQs were lower than the IQs of 175 healthy controls after adjusting for socioeconomic status and gender [10].

In our retrospective study, we demonstrate that a significant portion of patients with $\mathrm{CH}$ treated at the higher end of the recommended dosing range of LT4 became biochemically hyperthyroid requiring a dose reduction. Interestingly, we noted anecdotally that once the infants became hyperthyroid, these infants tended to take a longer period to normalize their TSHs. A mean time to normalize TSH in those requiring a dose reduction compared to the patients requiring no dose change or a dose increase could not be measured accurately due to inconsistent laboratory timing among providers.

Very few of the patients, 12 of 104, had not met the goal of normalizing TSH at follow-up visit. Most of these had only minimal elevation of the TSH. In fact only five of the 104 patients had a TSH of $>15$ mIU/L at follow-up and four of those five patients were treated with an initial dose of less than $11.4 \mu \mathrm{g} / \mathrm{kg}$. In contrast, $57.1 \%$ of infants treated with an initial dose of $>12.5 \mu \mathrm{g} /$ day required a dose reduction. Two prior studies have shown similar results. A study by Tuhan et al. [11] showed that the overtreatment rates were significantly higher at $61.5 \%$ in patients dosed at $12-17 \mu \mathrm{g} / \mathrm{kg} /$ day compared with the lowest dose group of $6-9.9 \mu \mathrm{g} / \mathrm{kg} /$ day at $25 \%$. In addition, a study by Vaidyanathan et al. [12] showed that at 1 month of treatment, the overtreatment rates were $37.5 \%$ for patients treated with $6-9.9 \mu \mathrm{g} / \mathrm{kg}$ daily, $55 \%$ in $10-11.9 \mu \mathrm{g} / \mathrm{kg}$ daily and $75 \%$ in $12-15 \mu \mathrm{g} / \mathrm{kg}$ daily. These studies and ours demonstrate that overtreatment has become a trend at multiple centers and needs to be addressed. 
Limitations of our study include the fact that compliance with frequent laboratory draws was low. In addition, there was variability among providers as to practice strategies. This variability included: the timing of the first follow-up laboratory test, dosage adjustments based on T4 levels, measurement of free T4 vs. total T4 for monitoring with TSH and the more recent strategy of using a higher dose and then lowering the dose at 2 weeks. The latter strategy does require increased compliance with laboratory testing. Another limitation of our study is while transient hypothyroidism was excluded, our practice does not routinely screen for the etiology of $\mathrm{CH}$ so there is no way to stratify groups based on etiology as suggested in other studies such as Mathai et al. [13] who initiated LT4 doses at 10, 12 and $15 \mu \mathrm{g} / \mathrm{kg}$ daily for dyshormonogenesis, ectopia and athyreosis, respectively.

In light of the significantly high overtreatment rates found in this and other studies, we suggest that a narrower dosage range for initial dosing of LT4 in $\mathrm{CH}$ may be appropriate. Certainly the risk and consequences of undertreatment of newborns with $\mathrm{CH}$ are real and to be avoided at all cost. However, this should not mean that optimal therapy that avoids both under- and overtreatment should not be the goal. In order to determine this range, a more regimented prospective study would be required. However, any potential refinement of the starting dose of LT4 would have to emphasize the need for testing TFTs every 2 weeks until the TSH normalized during initiation of treatment.

Author contributions: All the authors have accepted responsibility for the entire content of this submitted manuscript and approved submission.

Research funding: None declared.

Employment or leadership: None declared.

Honorarium: None declared.

Competing interests: The funding organization(s) played no role in the study design; in the collection, analysis, and interpretation of data; in the writing of the report; or in the decision to submit the report for publication.

\section{References}

1. Leger J, Olivieri A, Donaldson M, Torresani T, Krude H, et al. European Society for Paediatric Endocrinology consensus guidelines on screening, diagnosis, and management of congenital hypothyroidism. J Clin Endocrinol Metab 2014;99:363-84.

2. Harris KB, Pass KA. Increase in congenital hypothyroidism in New York State and in the United States. Mol Genet Metab 2007;91:268-77.

3. Rastogi MV, LaFranchi SH. Congenital hypothyroidism. Orphanet J Rare Dis 2010;5:17.

4. Grosse SD, Van VG. Prevention of intellectual disability through screening for congenital hypothyroidism: how much and at what level? Arch Dis Child 2011;96:374-9.

5. Rose SR, Brown RS, Foley T, Kaplowitz PB, Kaye Cl, et al. Update of newborn screening and therapy for congenital hypothyroidism. Pediatrics 2006;117:2290-303.

6. Bakker B, Kempers MJ, De Vijlder JJ, Van Tijn DA, Wiedijk BM, et al. Dynamics of the plasma concentrations of TSH, FT4 and T3 following thyroxine supplementation in congenital hypothyroidism. Clin Endocrinol (Oxf) 2002;57:529-37.

7. Selva KA, Mandel SH, Rien L, Sesser D, Miyahira R, et al. Initial treatment dose of L-thyroxine in congenital hypothyroidism. J Pediatr 2002;141:786-92.

8. Selva KA, Harper A, Downs A, Blasco PA, LaFranchi SH. Neurodevelopmental outcomes in congenital hypothyroidism: comparison of initial T4 dose and time to reach target T4 and TSH. J Pediatr 2005;147:775-80.

9. Bongers-Schokking J, Resing WC, de Rijke YB, de Ridder MA, de Muinck Keizer-Schrama SM. Cognitive development in congenital hypothyroidism: is overtreatment a greater threat than undertreatment? J Clin Endocrinol Metab 2013;98:4499-506.

10. Dimitropoulos A, Molinari L, Etter K, Torresani T, Lang-Muritano $M$, et al. Children with congenital hypothyroidism: long-term intellectual outcome after early high-dose treatment. Pediatr Res 2009;65:242-8.

11. Tuhan H, Abaci A, Cicek G, Anik A, Catli G, et al. Levothyroxine replacement in primary congenital hypothyroidism: the higher the initial dose the higher the rate of overtreatment. J Pediatr Endocrinol Metab 2016;29:133-8.

12. Vaidyanathan P, Pathak M, Kaplowitz PB. In congenital hypothyroidism, an initial L-thyroxine dose of $10-12 \mathrm{mug} / \mathrm{kg} / \mathrm{day}$ is sufficient and sometimes excessive based on thyroid tests 1 month later. J Pediatr Endocrinol Metab 2012;25:849-52.

13. Mathai S, Cutfield WS, Gunn AJ, Webster D, Jefferies C, et al. A novel therapeutic paradigm to treat congenital hypothyroidism. Clin Endocrinol (Oxf) 2008;69:142-7. 